\title{
Undergraduate University Education in Internet of Things Engineering in China: A Survey
}

\author{
Bing Du ${ }^{1}\left(\mathbb{D}\right.$, Yuke Chai ${ }^{1}$, Wei Huangfu ${ }^{1}{ }^{\mathbb{D}}$, Rongjuan Zhou ${ }^{2}$ and Huansheng Ning ${ }^{1, * \mathbb{C}}$ \\ 1 The School of Computer and Communication Engineering, University of Science and Technology Beijing, \\ Beijing 100083, China; dubing@ustb.edu.cn (B.D.); chaiyke@163.com (Y.C.); huangfuwei@ustb.edu.cn (W.H.) \\ 2 The School of Foreign Studies, University of Science and Technology Beijing, Beijing 100083, China; \\ zhourongjuan@ustb.edu.cn \\ * Correspondence: ninghuansheng@ustb.edu.cn
}

Citation: Du, B.; Chai, Y.; Huangfu, W.; Zhou, R.; Ning, H. Undergraduate University Education in Internet of Things Engineering in China: A Survey. Educ. Sci. 2021, 11, 202. https://doi.org/10.3390/ educsci11050202

Academic Editor: James Albright

Received: 24 March 2021

Accepted: 20 April 2021

Published: 25 April 2021

Publisher's Note: MDPI stays neutral with regard to jurisdictional claims in published maps and institutional affiliations.

Copyright: (c) 2021 by the authors. Licensee MDPI, Basel, Switzerland. This article is an open access article distributed under the terms and conditions of the Creative Commons Attribution (CC BY) license (https:/ / creativecommons.org/licenses/by/ $4.0 /)$.

\begin{abstract}
To address the problem of a serious Internet of Things (IoT) talent shortage, the Chinese government is encouraging universities and institutions to establish a major in IoT Engineering to train high-level IoT talent. Since 2011, 700 Chinese universities and institutions have established IoT Engineering undergraduate programs. We surveyed the history, status, curriculum, and problems of IoT undergraduate degree programs in China. Based on data collected from faculties, students, and graduates, we found that the IoT Engineering curriculum was an unsystematic patchwork and was deficient in practical platforms. We then provide suggestions for further development and exploration of IoT education by presenting a Technical Knowledge Map of IoT Engineering. This survey work on Chinese IoT education can prompt Chinese educators to reflect on its achievements and problems, which will contribute to IoT talent cultivation worldwide.
\end{abstract}

Keywords: Internet of Things (IoT); engineering curriculum; IoT engineering; interdisciplinary; undergraduate

\section{Introduction}

The Internet of Things (IoT) [1], which consists of the Internet and various sensors and activators, connects humans to humans, humans to things, and even things to things. It is being hailed as an industrial information revolution and is attracting attention from industrial, academic, and educational realms.

The concept of the IoT was first mentioned in The Road to the Future by Bill Gates in 1995, and then the term "IoT" was formally proposed by MIT Auto-ID Lab in 1999 [2]. The definition of the IoT was expanded in a report by the International Telecommunication Union (ITU) in 2005, which asserted that radio frequency identification (RFID) technology, sensor technology, nanotechnology, and intelligent embedded technology are the four core technologies of the IoT [3]. Thereafter, the IoT has had a key presence in the national development plans of many countries [4].

The rapid proliferation of the IoT has facilitated its research and application in many developed countries. The United States (US), as the pioneer in IoT technologies, launched the Smart Earth project. Then, many countries started IoT projects, including "The Internet of Things-An Action Plan" of the European Commission [5], the "U-Japan" plan of Japan, the "IT839" and "U-Korea" strategies of South Korea, the "Next-Generation I-Hub" plan of Singapore [6], and "Sensing China" in 2009. Further, China listed the IoT as one of its top five emerging strategic industries. The IoT has been regarded as a national strategy in many countries, with no efforts spared to promote its techniques and applications.

However, the promotion and sustainable development of the IoT has been confronted with a severe talent shortage [7-9]. Engineers and technicians with relevant skills and technologies in a specific branch of the IoT are indispensable for the development of the IoT. The talent shortage has been exposed as a major issue [10] during the promotion of the 
IoT. Obviously, with the increase in the application scale of the IoT, demand for IoT talent has increased sharply. However, The Internet of Things Talent Consortium investigated the impediments to success in digital transformation. The consortium surveyed 1500 senior executives, $50 \%$ of whom stated that the lack of digital expertise and skills is a main barrier. The world's largest survey of Chief Information Officers (CIOs) conducted by Gartner showed that $66 \%$ of CIOs believe that the demand for IoT talent will exceed the supply by a factor of five in 2021 [11]. As possibilities continue to arise in the IoT, the demand for IoT talent will continue to outpace supply, and universities need to play an active role in building the talent pipeline.

The giant skills gap is haunting the IT sector worldwide. According to the Industrial Internet of Things (IIoT) company PTC [12], it is estimated that in the next ten years, more than two million IoT-related jobs will be unfilled. IoT talent training in many countries has addressed the different skills needed in the IoT market, including user interfaces, wireless networking, artificial intelligence, and data processing. The education industry, i.e., universities such as Virginia Tech, Tsinghua, and Peking, and some online platforms such as coursera, has launched courses specific to IoT "modules". Most of these courses are still in their early stages, and few institutions have considered IoT as a stand-alone undergraduate degree program. Such IoT training programs are just stopgap measures. To the best of our knowledge, only a small number of universities outside of China offer majors related to the IoT, as shown in Table 1, and the majors listed include undergraduate and graduate programs.

Table 1. Universities with IoT Engineering majors outside China.

\begin{tabular}{|c|c|c|c|}
\hline University & Major & Degree & Emphases \\
\hline Florida International University & Computer Engineering: IoT & Bachelor & $\begin{array}{l}\text { 1. IoT programming } \\
\text { 2. Cybersecurity } \\
\text { 3. IoT hardware design }\end{array}$ \\
\hline Waterford Institute of Technology & IoT & Bachelor & $\begin{array}{l}\text { 1. Embedded sensors } \\
\text { 2. Mobile phones } \\
\text { 3. Single board computers } \\
\text { 4. Cloud systems }\end{array}$ \\
\hline University of Sydney & Electrical Engineering: IoT & Bachelor & $\begin{array}{l}\text { 1. Wireless communications } \\
\text { 2. Networks } \\
\text { 3. Sensor devices } \\
\text { 4. Data technologies }\end{array}$ \\
\hline Royal Holloway, University of London & IoT & Master & $\begin{array}{l}\text { 1. Data analytics } \\
\text { 2. Distributed computing } \\
\text { 3. Distributed systems } \\
\text { 4. Cybersecurity } \\
\text { 1. Self-adaptive systems }\end{array}$ \\
\hline Malmö University & Computer Science: IoT & Master & $\begin{array}{l}\text { 2. Cyber physical systems } \\
\text { 3. Systems of systems } \\
\text { 4. Engineering of all systems } \\
\text { 1. Acquire data }\end{array}$ \\
\hline Queen Mary University of London & IoT & Master & $\begin{array}{l}\text { 2. Process data } \\
\text { 3. Interact with things } \\
\text { 4. Interconnect things } \\
\text { 1. IoT ecosystem } \\
\text { 2. Data science }\end{array}$ \\
\hline University of Oxford & Data Science for IoT & Certification & $\begin{array}{l}\text { 3. Programming } \\
\text { 4. Problem solving } \\
\text { 5. Online engagement } \\
\text { 1. RFID }\end{array}$ \\
\hline MIT & IoT & Certification & $\begin{array}{l}\text { 2. Cloud technology } \\
\text { 3. Sensors } \\
\text { 4. WWW technology }\end{array}$ \\
\hline Stanford University & Online: IoT & Graduate Certification & $\begin{array}{l}\text { 1. Sensors } \\
\text { 2. Embedded systems } \\
\text { 3. Networking } \\
\text { 4. Circuits }\end{array}$ \\
\hline
\end{tabular}


Florida International University, Waterford Institute of Technology, and the University of Sydney have established exclusive IoT bachelor's degrees for undergraduate students, but they put different emphases on their IoT technologies. More universities are aware of the importance of the IoT and have chosen to open a master's degree program, focusing on in-depth research on IoT technologies. Other universities, e.g., the University of Oxford and MIT, are offering certifications for IoT training. Their approach is to add the core courses on IoT techniques to the curriculum of Computer Science (CS) or Electronic Engineering (EE), such as data science, RFID, cloud technologies, and sensors. These courses, designed for developers targeting the IoT, help students to develop a good grasp of mathematics and the abilities to use databases, large-scale datasets, and commercial data products such as MapR, Numenta, and MongoDB that cover the IoT ecosystem, data science, problem solving, online engagement, and programming languages. Stanford University offers a six-week, online graduate program for market calling. Stanford University also revised the EE undergraduate program to offer IoT-related courses such as digital design, embedded software, and wireless communications. In sum, only a few universities outside China have independent IoT majors, and there is no unified and clear training goal for these IoT professionals.

Chinese universities set a stand-alone undergraduate program called "IoT Engineering" in 2010, which is parallel to CS and EE. Now there are 700 universities and institutions that offer IoT undergraduate programs, as shown in Figure 1. As early as 2012, we [13] discussed the classification of IoT technologies and the corresponding educational issues, and raised the issue of whether to set IoT as a stand-alone undergraduate program. However, issues such as the educational planning, curriculum setting, and pedagogy of IoT Engineering are still in the investigation stage.

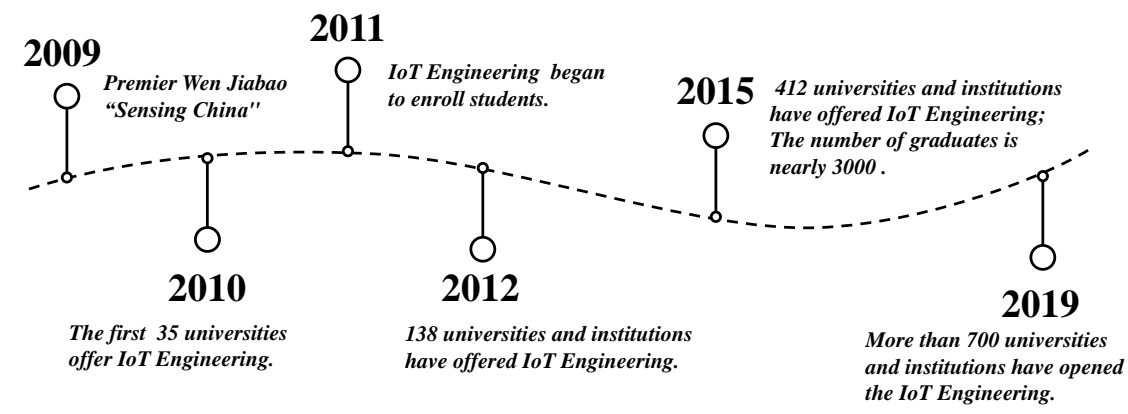

Figure 1. Development process of IoT Engineering majors in China.

This paper is a survey of the undergraduate degree programs in IoT Engineering in China. Our goal is to share practical and valuable implementable experiences to accelerate IoT industries. The major tasks of the paper are summarized as follows.

Background: To address the serious IoT talent shortage problem, the Chinese government is encouraging universities and institutions to establish a major in IoT Engineering to train high-level IoT talent. Since 2011, 700 Chinese universities and institutions have established IoT Engineering undergraduate programs.

Purpose: (1) What are the major problems of IoT undergraduate programs in China? (2) How can we ensure qualified training in IoT Engineering? (3) How can we meet the demand from enterprise and society for IoT talent?

Method: We surveyed the history, status, curriculum, and problems of Internet of Things (IoT) undergraduate degree programs in China. Based on data collected from faculties, students, and graduates, major problems of the IoT Engineering curriculum being an unsystematic patchwork and being deficient in practical platforms are revealed. We then provide suggestions for decision-makers to further develop and explore IoT education by presenting a Technical Knowledge Map of IoT Engineering. The closed-loop Technical Knowledge Map can be considered a guide to connect IoT theories with practical training for IoT Engineering undergraduate programs. 
Conclusion: China was the first country to set IoT Engineering as a stand-alone undergraduate program. The pioneering work on IoT education in China can prompt Chinese educators to reflect on its achievements and problems, which will contribute to IoT talent cultivation worldwide.

The paper is organized as follows. Section 2 presents a general overview of the undergraduate IoT education in China, including its history, its current status, and the existing problems during its development. Section 3 proposes an IoT talent training model for universities and institutions based on a Technical Knowledge Map of IoT Engineering. Section 4 analyzes the development trend of IoT education in the era of 5G and intelligence. Section 5 presents the conclusions.

\section{Overview of IoT Education in China}

\subsection{The History of IoT Education in China}

As early as 2009, China's Premier Wen Jiabao identified the IoT as one of five "strategic emerging industries", which implied that China began to embrace the groundbreaking implications of the IoT at a high level [14]. Since 2009, a variety of state plans in different IoTrelated fields have been launched to realize wide-ranging IoT development in China. Given the rate at which IoT technologies are accelerating in complexity and potential applications, voices from many industries and research backgrounds are calling for universities and institutions to train highly qualified talent in IoT engineering. Many universities have joined in the exploration of IoT education, thirty-five of which took the lead to found undergraduate programs in "IoT Engineering" and "Sensor Network" in 2011 [15]. The number of universities which opened IoT Engineering programs soared to 138 in 2012. Those universities stated clearly in their curricula that the IoT program was a four-year undergraduate degree program that offered the Bachelor of Engineering upon completion of study. From 2015 to 2019, the number of universities and institutions setting up IoT degree programs increased from 412 to more than 700. Based on statistics from MyCOS, a Chinese consulting corporation for post-secondary education [16], the average employment rate of the graduates in 2017 to 2019 was $94 \%$ (Table 2; the number of statistical samples was 10,000 , and the population counted in the employment rate included persons who were employed and continuing their studies).

Table 2. Statistics for graduates of IoT Engineering majors.

\begin{tabular}{cccc}
\hline Key Indicators & 2019 Graduates & 2018 Graduates & 2017 Graduates \\
\hline Employment rate $^{1}(\%)$ & 93.1 & 94.3 & 94.5 \\
Monthly income (RMB) $_{\text {Relevance between the job and }}$ & 6671 & 6420 & 5826 \\
the IoT professional (\%) & 70 & 74 & 74 \\
Job satisfaction (\%) & 70 & 72 & 73 \\
Teaching satisfaction (\%) $_{\text {Course importance }}^{2}(\%)$ & 89 & 88 & 87 \\
Course satisfaction $^{2}(\%)$ & 80 & 79 & 76 \\
\hline
\end{tabular}

${ }^{1}$ The population counted in the employment rate included persons who were employed and continuing their studies. ${ }^{2}$ The statistics of the course importance and course satisfaction are from people engaged in IoT-related work. The data are from [16].

However, there has been a dispute about whether to set up an IoT major at the undergraduate stage. The standards, technologies, business models, and supporting policies related to IoT are not yet mature. So far, IoT Engineering in academia and some research institutions is still in the developing stage. The embarrassing status quo of "no teachers", "no teaching materials", and "no laboratories" has become a gulf facing the training of high-level talent in IoT. Because there are not enough dedicated faculties in the IoT major, it is common for colleges and universities to "borrow" teachers from related majors such as electronics, computer, and communications. In addition, some colleges and universities have relatively weak platforms to offer IoT teaching. The vice president 
of China Internet of Things Industry Association, Siwei Bai, said that it was not the right time to set up an IoT Engineering major at the undergraduate stage right now [17]. He asserted that CS and IoT Engineering overlapped considerably. Adding IoT-relevant content to existing CS courses was rather a better option. Ning and Hu [18] also mentioned that IoT Engineering as an independent program at the undergraduate stage did not fall into place because IoT is interdisciplinary and involves an extensive range of knowledge, more like a system of systems, which poses great challenges for universities to set up an exclusive major covering full aspects of IoT technologies and applications. Therefore, a postgraduate program is more appropriate to pursue IoT technologies as a profession. For instance, Tsinghua University and Peking University, the top two universities, do not have undergraduate programs. However, in April 2010, Tsinghua University built an IoT research center in the CS department. Peking University established a program of Intelligent Science and Technology that offers IoT courses such as artificial intelligence (AI), machine learning, data processing, and cloud computing. Besides, Peking University also built an IoT application research center.

It has been claimed that domestic colleges and universities used the excuse of talent training to create impressive-sounding money-making gimmicks. Have colleges and universities entered the era of "using the Internet of Things to obtain scientific research funds"? At the same time, nongovernmental training in IoT is gaining momentum. When will the chaos in the cultivation of IoT talent end? Although there is controversy about whether IoT Engineering should be regarded as a stand-alone major, almost all the universities in China have realized the significance of IoT research, and many have opened undergraduate programs in IoT engineering.

\subsection{The Curriculum of IoT Engineering}

Since 2011, IoT Engineering has been a flourishing, new undergraduate engineering degree program that aims to cultivate talent for the full development of IoT. Among 700 universities, there exist huge differences in the positioning of training, the curriculum setting, the practical teaching, and comprehensive innovation ability [10]. Burd et al. identified four approaches to integrate IoT concepts and courses into university curricula: (1) broad introduction course on IoT; (2) integrating existing courses with IoT; (3) focused course as part of an IoT specialization; (4) courses on specific IoT use-cases. Moreover, on the basis of the data from the National Center of Information Consultation and Employment Guidance [19], we classified the curriculum of IoT Engineering into two modes: full coverage and biased coverage, according to their characteristics as follows.

\subsubsection{Full Coverage Mode}

IoT Engineering is an interdisciplinary subject that involves Computer Science, Electronic Engineering, Communication Engineering, and Automation Engineering. At the beginning, most universities tried to cover all the disciplines and various technologies of IoT. They incorporated the courses across the sensing layer, network layer, supporting layer, and application layer of the IoT framework to develop a full curriculum system [20], called the full coverage mode, as shown in Table 3. They offered courses inherited either from CS or EE or both. They shared the same fundamental courses with the traditional CS or EE courses, and they added courses, such as "Introduction to IoT", "IoT sensing technology", "IoT control system and technology", and "IoT system integration and application", to characterize "IoT Engineering". The major deficiency of the curricula with full coverage mode was that the courses did not relate to each other. Although named with "IoT", their contents did not combine IoT technologies organically, but were just a simple summation. For instance, in Table 4, the IoT Engineering curriculum of Huazhong University of Science and Technology is listed. Some of the courses were inherited from CS and EE, whereas others were overviews related to IoT. It seems that all aspects of IoT research are covered, but organized loosely, only being in the shallow water of the sea. This is a common problem in IoT Engineering with full coverage mode. 
Table 3. The classification of the curriculum settings of IoT Engineering majors.

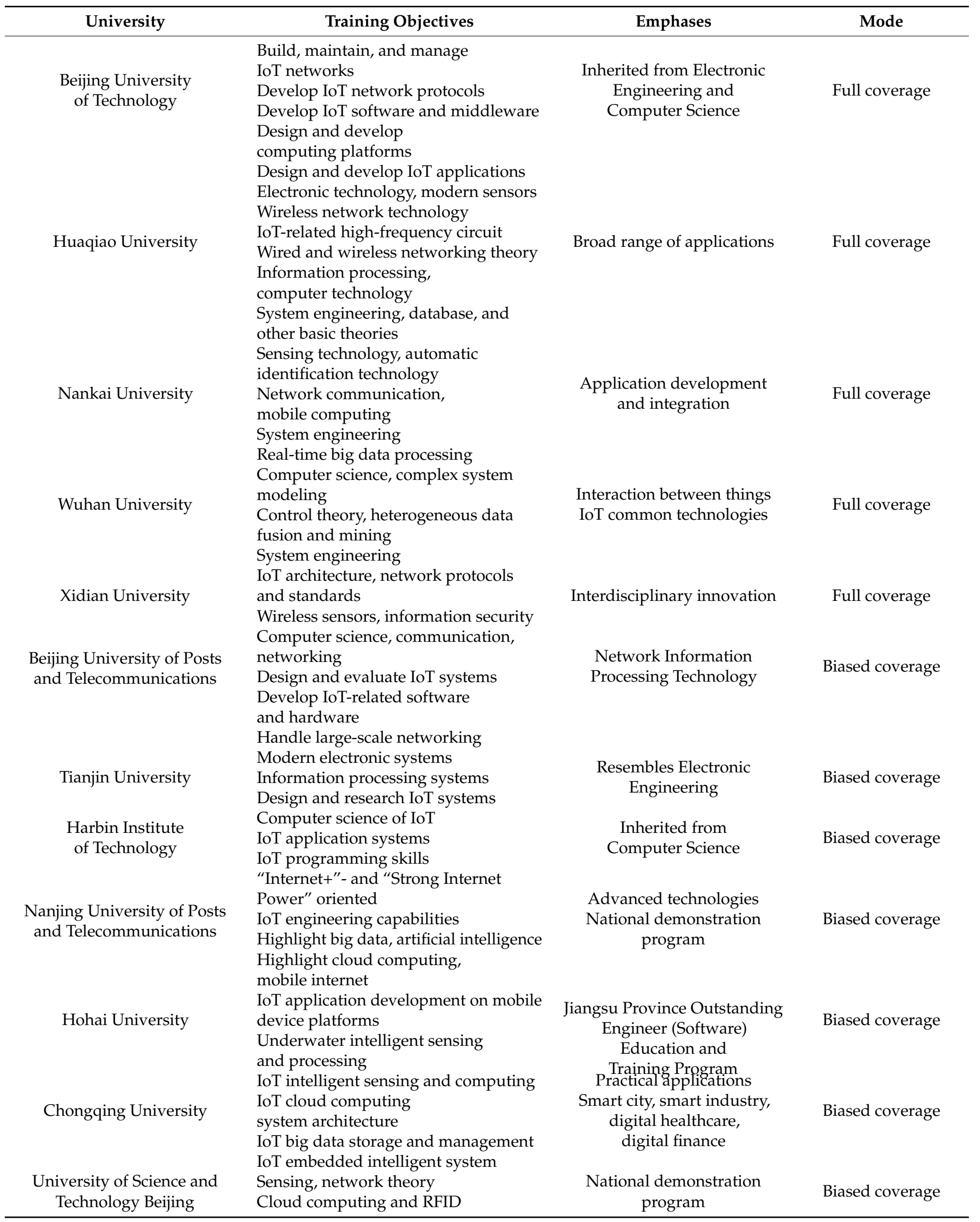


Table 4. The curriculum of IoT Engineering.

\begin{tabular}{ccc}
\hline University & Curriculum & Inheritance \\
\hline & $\begin{array}{c}\text { data structures, database principles, } \\
\text { microcomputer interfaces }\end{array}$ & CS \\
\cline { 2 - 3 } $\begin{array}{c}\text { Huazhong University of } \\
\text { Science and Technology }\end{array}$ & $\begin{array}{c}\text { microelectronics and IC design, embedded } \\
\text { operating system, RFID and sensors }\end{array}$ & EE \\
\cline { 2 - 3 } & $\begin{array}{c}\text { IoT communication, computer network } \\
\text { IoT middleware, introduction to IoT, }\end{array}$ & \multirow{2}{\text{IoTSecurity}}{ IoT overview } \\
\cline { 2 - 3 } & $\begin{array}{c}\text { IoT Data Storage and Management, IoT } \\
\text { Application System Design }\end{array}$ & \\
\hline
\end{tabular}

A graduate satisfaction survey suggested that IoT Engineering was not as good as CS and EE [16]. Some of the graduates said it was not easy to clearly follow IoT Engineering. Lack of a systematic curriculum made it difficult for students to understand what they had learned.

Most of the IoT curricula in Chinese universities belong to the full coverage mode. It is also noted that there are variations in the curriculum design among universities in terms of their respective subject characteristics and teaching conditions.

\subsubsection{Biased Coverage Mode}

At present, in China, few universities have set up independent departments for IoT Engineering. Most of the universities put IoT Engineering in their prominent departments, such as in CS or EE. Therefore, their IoT Engineering curricula always had different emphases, as shown in Table 3.

Most top universities in China, such as Harbin Institute of Technology, University of Science and Technology Beijing, and Jilin University, placed IoT Engineering in CS departments, and the courses focused more on the application of IoT, especially on IoT software and IoT systems. Other universities, such as Shandong University of Science and Technology, Tianjin University, and Wuhan University of Technology, set up IoT Engineering in the EE department or Automation department. Their curricula focused more on IoT sensing and control technologies, specifically on sensors, RFID, microcomputers, and embedded systems. Also, an IoT program was possibly offered by the Communications department, such as at the University of Electronic Science and Technology of China. The courses focused on IoT networking, IoT wireless communications, information sensing, and processing. These universities constructed IoT curricula according to their faculty professionals, oriented to the personnel's training in one of the areas, such as IoT sensors, IoT wireless technologies, and IoT programming. We call this biased coverage mode.

The biased mode concentrates on some particular IoT technologies, and it establishes an IoT Engineering major with the aid of the superior majors under the affiliated departments. This approach can cultivate more specialized professionals and promote a diversity of talent. However, it is not a developed mode of IoT Engineering because it lacks the systematic structure to depict a full dimensional portrait of IoT Engineering for students.

\subsection{Problems in IoT Engineering}

Regardless of adopting the full coverage mode or the biased coverage mode, many universities and institutions coincidentally chose to establish an IoT Engineering major with the support of their forefront disciplines in related research areas. However, there still exists a gap between the market demand and the skills the students acquire from university. In particular, after they enter the employment market, the existing problems or weaknesses in current IoT Engineering curricula will be exposed. Huang et al. [21] pointed out that the current IoT Engineering has unfocused training objectives and a broad curriculum, which results in low student capabilities. Yan et al. [22] attributed the shortage of IoT talent to the 
outdated curricula, isolated content, and poorly qualified faculty. Ren et al. [23] pointed out that there are insufficient teaching reform and scientific research activities related to IoT in universities. Thus, we summarize the major common problems in IoT Engineering in universities.

\subsubsection{Broad Training Objectives}

As shown in Table 3, the IoT program is a multidisciplinary subject and the fundamental theory covers multiple disciplines. Without careful planning and organizing, some universities easily fall into a situation in which IoT Engineering is merely a compact version of a simple combination of EE and CS, resulting in a curriculum without "soul". That is, the objectives are not clear, and they are relatively broad descriptions. For example, the University of Science and Technology Beijing's IoT Engineering training objectives are: learn the fundamental IoT theories, and be capable of designing, developing, and applying computer technology, microelectronics technology, and multimedia and information processing technology after graduation [24]. Wuhan University's IoT Engineering training objectives are: to cultivate compound talents with professional knowledge and skills in computer science, complex system modeling, control theory, heterogeneous data fusion and mining, and systems engineering [25]. These objectives require students to master the relevant skills of four disciplines, but they do not specify which skills are most important. With vague guidance, universities will be unlikely to design a systematic and effective curriculum.

\subsubsection{Divergent Curriculum Design}

As for the curriculum, IoT Engineering in most Chinese universities and institutions belongs to the full coverage mode. Only one year after China proposed the development of IoT, universities and institutions opened the major of IoT Engineering. Hence, the easiest way to establish an IoT Engineering major is to combine some existing IoT-related courses from EE and CS. Therefore, the connection between those courses tends to be weak, and the schedule of the courses may appear random; thus, the students cannot learn step-by-step. The graduates may not have well-rounded skills in IoT because of the "patchy" curriculum. Moreover, because of the limited credit hours, the curriculum provides students with all-around but less profound IoT knowledge.

University of Science and Technology Beijing (USTB) is one of the first 35 universities in China to establish an IoT Engineering major. USTB developed IoT Engineering in the Department of Computer Science and Communication Engineering in 2010. Recently, IoT Engineering at USTB became a national-level prominent major. The employment rate of graduates has been $97 \%$. The curriculum of IoT Engineering at USTB is shown in Figure 2; it involves three key aspects of IoT technologies: devices, communication, and data processing. The number of courses is enough, but the courses are somehow divergent in an IoT framework.

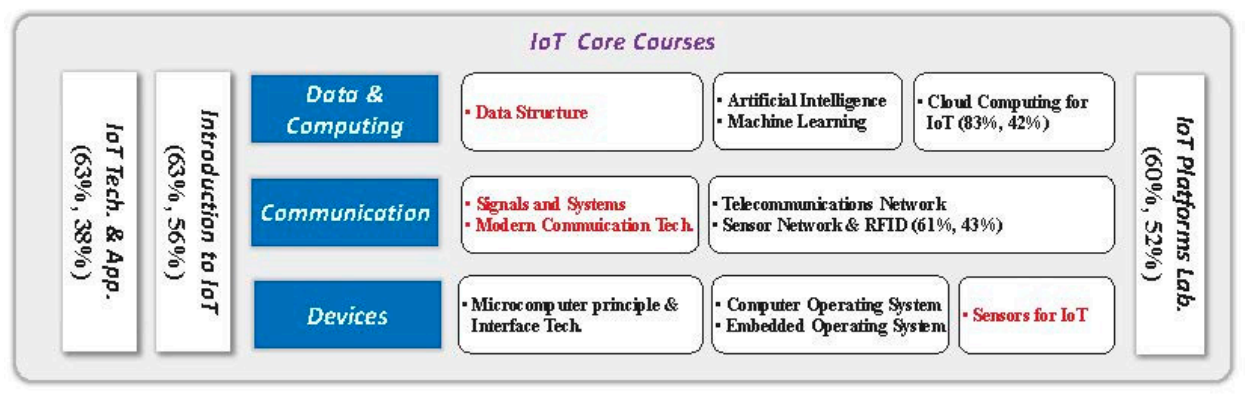

Figure 2. IoT Engineering core courses at University of Science and Technology Beijing. The first percentage is the course importance, and the second percentage is the course satisfaction. 
"Introduction to the IoT" in Figure 2, a compulsory introductory course of IoT Engineering, covers a wide range of essential technologies, including sensor technology, IoT security, cloud computing, big data, and intelligent processing, any of which can be extended to a complete and comprehensive independent course. However, this course is compacted into 64 credit hours, far from being adequate, for both teachers and students. Moreover, the courses have considerable overlap. For instance, "Microcomputer Principle and Interface Technology", "Single-Chip Microcomputer Principle", and "Embedded System" contain much common content, such as the hardware of the microcomputer and the interface technology. Therefore, a more balanced curriculum in terms of the course priorities, credit hours, and schedule should be addressed to reflect a reasonable knowledge structure.

In Figure 2, in the category of "Devices", "Sensors for IoT" in red font has no preliminary courses regarding chips and algorithms, such as Circuit Analysis, Analog Electronic Technology, or Digital Electronic Technology. Without these preliminary courses, the students often stay on the surface of the technologies, and it is difficult to deepen and widen their knowledge. In the category of "Communication", "Signal and System" is not the best option for introducing basic communication technology. Instead, "Communication Principle" can deliver necessary preliminary content for later courses such as "Telecommunication Network" and "Sensor Network". Without "Communication Principle", the course "Modern Communication Technology" can hardly achieve its goal. In the category of "Data and Computing", big data is one of the top challenges for IoT; however, only one course about big data is delivered. More courses on big data should be involved in IoT Engineering.

Figure 2 presents two statistics, the course importance and course satisfaction. MyCOS [26] surveyed new graduates and calculated the two statistics. The training effect of the core courses of each major at USTB is shown in Figure 3. The horizontal axis in the four-quadrant figure indicates the course importance, and the range covers the maximum and minimum values of the importance of the core courses of each major at USTB. The vertical axis represents the course satisfaction, and the range covers the maximum and minimum satisfaction scores of the core courses of each major. For simplicity, we list only a few majors related to IoT. Noticeably, more than $50 \%$ of the graduates from IoT Engineering did not approve of the curriculum setting. The course importance and the course satisfaction were low. IoT Engineering at USTB requires effective countermeasures to improve training quality.

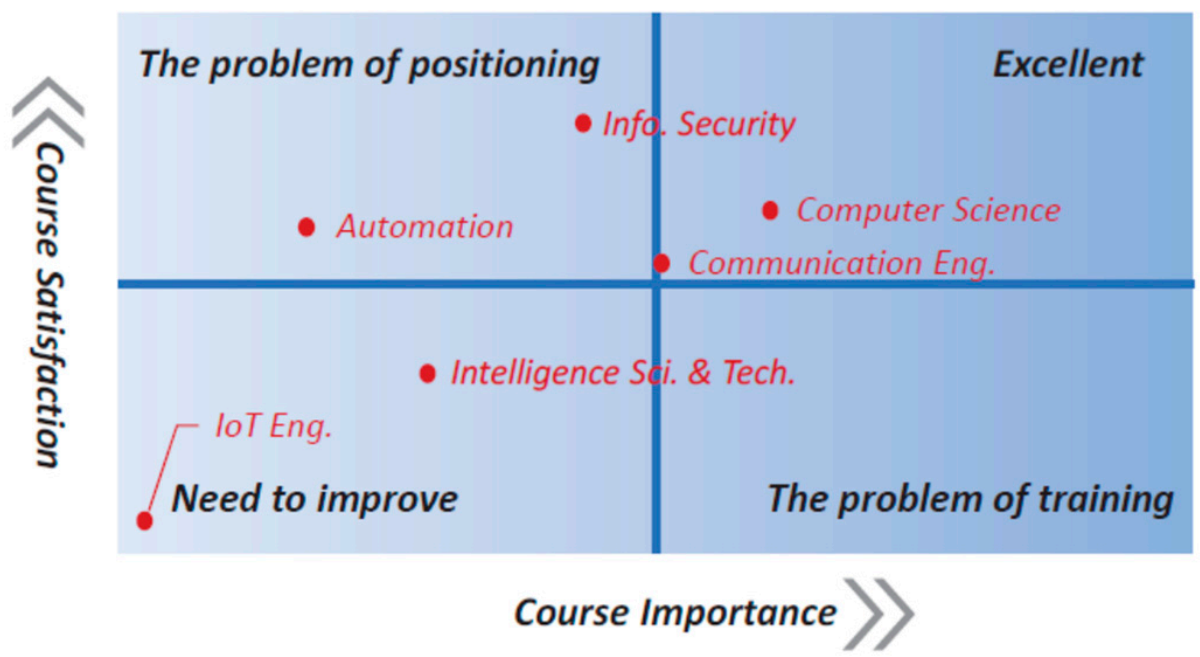

Figure 3. Comprehensive evaluation of the core courses of each major at USTB. 


\subsubsection{Deficient Practical Skills Training}

IoT Engineering should emphasize quality training in engineering, enabling graduates to work as IoT engineers or IoT developers. IoT Engineering is highly comprehensive [27], which poses difficulties for teaching both theory and practice. Some universities pay more attention to theory than practical training. Skills training, especially IoT solution training, is often ignored. We would hope that graduates would be able to troubleshoot IoT devices as software engineers, learn how to program smart devices, and work on IoT solutions in all essential economic sectors. As such, the universities offering IoT Engineering should provide an IoT practical platform to combine software training with programming and hardware expertise. This IoT platform should be well developed in a specific research field in which IoT can be involved, such as smart home, smart city, intelligent transportation, smart healthcare, and smart manufacturing. However, most universities do not have such an IoT platform exclusively for skills training. Although some universities have dedicated IoT laboratories and conduct many IoT-related projects, the training and practice courses are isolated from undergraduates.

In addition to lacking equipment, the content of the practical courses is outdated and difficult to adapt to new technologies. Such poor training programs cannot help students possess engineering skills. Almost all the IoT core courses should parallel practical training. The credit hours are limited, so the skills training courses should be integrated into a demonstrated IoT platform, which incorporates all of the IoT technologies delivered in the university. This platform can be a win-win program. The students can perfect their IoT engineering skills, such as programming, hardware design, and data processing, and even try to give an IoT solution for any projects that the IoT platform is conducting. In addition, training is a process that can accelerate IoT research.

For now, only a few universities in China have such supporting platforms. Hohai University established Jiangsu Province Electronic Information Technology Experimental Demonstration Center and Changzhou Key Laboratory of Sensor Network and Environmental Awareness to conduct IoT programs, in which they optimize the overall IoT curriculum system and knowledge structure, paying attention to the penetration of arts and sciences, integration of science and engineering, and improvement of innovation and practical ability. Jiangnan University's School of IoT Engineering was formed in 2010 by merging its former Schools of Communication and Control Engineering with Information Engineering. The School of IoT Engineering has a partnership with the major German multinational engineering and electronics company Bosch $\mathrm{GmbHb}$ centered on vehicular IoT services. Nanjing University of Posts and Telecommunications (NUPT) established the College of IoT in 2009 as a merger of NUPT's IoT Engineering and Network Engineering programs. NUPT's College of IoT is associated with NUPT IoT Technology Park, a joint project of NUPT and the Nanjing Gulou District municipal government established in 2010, focusing on IoT technical advances. Xiamen University of Technology has housed a Provincial Key Laboratory of IoT Applied Technology since 2012, functioning as a partnership with Xiamen Industrial Technology Research Institute. However, the platforms mentioned here take advantage of the south-eastern superior IoT industries and cooperate with the industries to provide powerful teaching and research test beds. Other than that, few IoT platforms are dedicated to undergraduate programs.

\section{Suggestions for IoT Engineering}

In view of the problems discussed above, we propose a talent training model for IoT Engineering in this section.

\subsection{Formulate Specific Training Objectives}

IoT technology is constantly updating and expanding. To have the skills to adapt to the market demand, universities and institutions should conduct surveys of enterprises and markets to assess the prospect of their demand for IoT talent and ever-growing technology trends. According to the survey results, universities and institutions would formulate IoT 
training objectives, with consideration of faculty, software and hardware conditions, and their superior majors. The training objectives would not only give full play to the respective advantages of universities and institutions, but also align with the needs of society and industry. Specifically, there are four steps to formulate the training objectives as per the university characteristics:

1. Survey the enterprises and markets to obtain the pressing requirements for IoT talent;

2. Refine the existing laboratory research resources and list the possible leading IoT technologies;

3. Incorporate these IoT technologies into an integrated training platform;

4. Formulate practicable training objectives for the specific skills.

\subsection{Build a Convergent Curriculum System}

In accordance with the established talent training objectives, a convergent curriculum system of the IoT program needs to be developed, with reference to the leading IoT technologies in the university and scientific structure of the IoT industry.

For formulating the curriculum system, we propose a Technical Knowledge Map of IoT Talent (TKM-Map) for the universities' and institutions' reference, as shown in Figure 4. The TKM-Map is depicted in a four-layer IoT framework with two supporting technologies, covering all major IoT research interests, in which the core courses stem from the fundamental ground to the upper level. We cannot say that the TKM-Map has covered all aspects of IoT industries. With this TKM-Map, universities and institutions should develop their own IoT curriculum map and try to create an integrated framework.

IoT Platforms Lab.

Smart City, Smart Home, Smart Healthcare, intelligent Transportation, Smart Manufacturing, Smart Energy, Smart Retail, Smart Logistics, Smart Agriculture, Smart Building, etc.

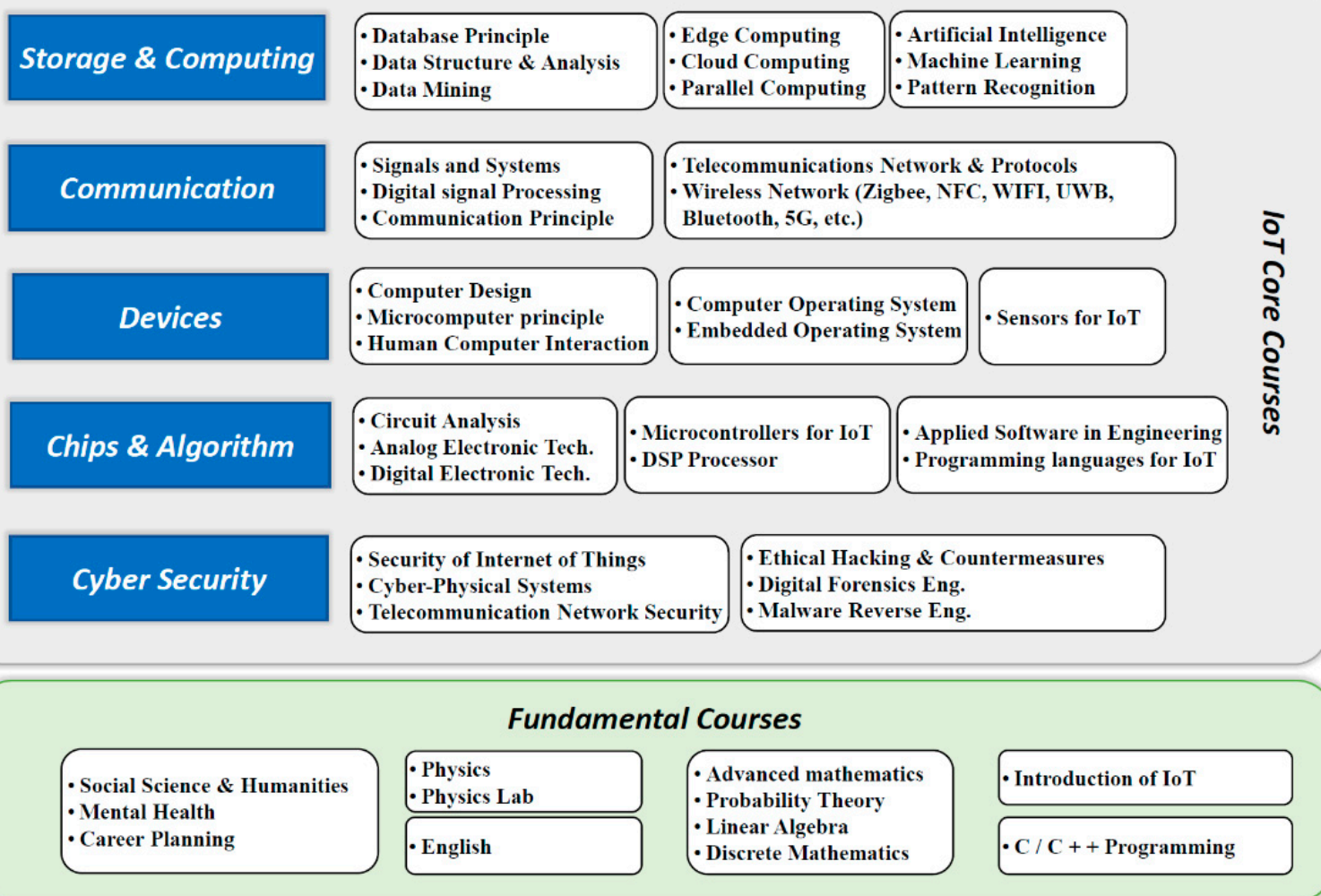

Figure 4. The Technical Knowledge Map of IoT Talent. 
The bottom rectangle in the TKM-Map is the fundamental courses that IoT Engineering students need to take, including general courses and basic courses. The courses are offered in the freshmen year at most universities and institutions. General courses mainly include social science and humanities, English, and career planning. Basic courses include physics, advanced mathematics, and probability theory, which mainly lay the foundation for later professional learning.

The middle rectangle, the major part of the TKM-Map, incorporates the core courses of IoT Engineering, including a four-layer architecture and two common technologies, security and algorithm. A four-layer structure of IoT is referenced in terms of the function of IoT, which can be divided into the following parts.

\subsubsection{Sensing Layer}

Intelligent sensing functions as the major data source of IoT to collect data and information from the peripheral environment or objects by chips, devices, and sensors. At the technical level, employees are supposed to obtain knowledge in chips, sensors, RFID, and QR code. At the course level, the related courses are divided into five subcategories: (1) preliminary requisites on the circuit, including circuit analysis and analog and digital electronic technology; (2) microprocessor technologies on DSP processor and microcontrollers for IoT; (3) sensors for IoT; (4) computer or microcomputer design and human-computer interaction; (5) computer and embedded operating system. The courses of the "sensing layer" are set according to the line "circuits $\rightarrow$ processors $\rightarrow$ sensors $\rightarrow$ (micro) computers $\rightarrow$ operating systems", which is clear and logical.

\subsubsection{Transmission Layer}

Data transmission in IoT is fulfilled by the integration of communication, network, and information, based on the existing mobile communication network and the Internet to exchange and share the information.

The major technology is wireless communication, including short-distance wireless communication technology (SD-WCT) and long-distance wireless communication technology (LD-WCT) [28]. Short-range wireless technologies, such as Bluetooth, Wi-Fi, and ZigBee, are usually used to connect equipment, products, and intelligent terminals. However, in some cases where short-distance wireless transmission cannot meet the needs of the application, long-range communication technologies should be engaged, such as 3G, 4G, LoRa (Long Range), Sigfox (an ultra-narrowband technology), NB-IoT (Narrowband Internet of Things), and Low-Power Wide-Area (LPWA) network transmission technologies. With the ever-growing technologies, 5G will be an enabler across a myriad of industries and applications, and likely spur new use-cases. Other technologies, such as cable communication transmission, Machine-To-Machine (M2M), and triple play, can be taken as options.

At the course level, relevant courses include: (1) preliminary courses: signal and system, digital signal processing, and communication principle; (2) upper-division courses: computer network, network protocols, and wireless network. The design concept behind the courses is from point-to-point communication to network information theory and technologies.

\subsubsection{Processing Layer}

Information processing technology is the key to IoT development. Processing will store, retrieve, analyze, and utilize the data obtained from the sensing layer.

At the technical level, IoT processing technologies mainly focus on big data storage and computing because of the massive amount of data generated by universal IoT. The storage of big data is necessary for limited resources and real-time access. Distributed, parallel computing and computing of different levels can effectively enable information acquisition and data sharing on various devices.

At the course level, the following courses need to be offered: (1) database principles, data structure, and data mining; (2) edge computing, cloud computing, and parallel and 
distributed computing. The design concept simply follows the technology requirements for storage and computing.

\subsubsection{Application Layer}

Ten hot IoT application industries have developed in recent years, such as Smart Logistics and Smart Transportation. IoT undergraduates need to understand the concepts in those applied fields. For instance, an agricultural university should interpret the concept of Agricultural IoT, using IoT to realize intelligent identification, tracking, query, and management of agricultural production, further expanding to intelligent logistics and sales. Therefore, relevant agricultural courses, such as "Practical Training in Modern Agricultural Science and Technology", "Practical Training in Forestry IoT Technology", should be delivered for IoT Engineering students. Generally, the practice courses should be offered in terms of the university's field of expertise, and they should be based on practical projects that have actual data and real problems to be solved. Such courses are more difficult to design than normal experimental courses because these practical projects must be modified to reflect the key skills that undergraduates should have. Therefore, setting up IoT Engineering is not just a plan; the university should possess an integrated IoT platform that supports specific IoT-related research and can be adapted to an undergraduate training program.

In addition to the courses based on this four-layer architecture, two supporting technologies - cyber security and algorithms - are spread across all of the four layers.

\subsubsection{Cyber Security}

With the increasing number of IoT devices, aggregation of IoT applications, and the centralized management of data platforms, security and privacy protection have drawn much attention in IoT research fields [29]. Huang et al. [30] analyzed the IoT security requirements of the four layers and proposed a security model for IoT.

Security technologies are involved in the four layers. The sensing layer must guarantee the security of the physical operation and sensor data [31]. It uses lightweight encryption authentication technologies, data encryption storage, and mutual authentication to strengthen security [32]. The transmission layer must ensure the confidentiality and integrity when transmitting data to the remote processing platform [33], involving network security, Virtual Private Network (VPN), key authentication intrusion detection, and virus detection. The processing layer ensures the effective database access control, content processing, and reliable key management mechanism. Also, it should be capable of intrusion detection, cryptography, secure multiparty computing, and secure cloud computing. For the application layer, different industries need different data processing technologies and security requirements [34]. However, on the basis of these security requirements, industry commonly uses privacy protection, mobile terminal equipment security, intrusion detection, and cryptography.

Courses related to cyber security include two categories: self-protection and antiattack. In self-protection, telecommunication network security can be taken as the basis. The cyber-physical system is the architecture, and security of IoT focuses on the detailed technologies. In the anti-attack category, ethical hacking and countermeasures, digital forensics, and malware reversal can be good options. In fact, security can be regarded as a separate discipline, which requires a broad range of knowledge. In this paper, we give only a simple suggestion from the perspective of IoT.

\subsubsection{Algorithms}

The algorithm is also the master in all four layers, helping students to understand and then realize IoT design objectives.

As the preliminary knowledge, applied software engineering is an introduction to and overview of the software technologies in IoT. Moreover, some programming languages are more popular in the IoT application area: 
- Python was scored third in the IoT Developers Survey 2019. Python is compatible with IoT because of a vast developer community and a large number of libraries and tools.

- Go, created by Google, is popular in IoT because of its performance features that maximize hardware use, which makes the language compatible with IoT devices.

- Java and JavaScript are popular choices for developers of IoT applications. Java and JavaScript dominate IoT cloud applications according to the IoT Developers Survey 2019.

- $\quad$ PHPoC (PHP on Chip) can be seen as an IoT hardware platform that is developed based on the widely used PHP language, which makes PHPoC not only a Web development language but also a general-purpose IoT programming language.

In addition, AI cannot be neglected when it comes to IoT. Therefore, artificial intelligence, machine learning, and pattern recognition should be added to the curriculum to keep up with the technology. These courses can be merged into one, as an introduction to the cutting-edge IoT technologies.

The TKM-Map is only a reference. In practice, because of the limitation of credit hours, it is impossible to offer all the courses. The most feasible solution is to build a favorable curriculum based on the available resources and training objectives, and then schedule the most relevant courses in a reasonable sequence. The courses in each rectangle in the TKM-Map can be merged into one with careful content design, if there are not enough credit hours. Such a curriculum not only reflects the professional characteristics of IoT, but also highlights the academic advantages of the program.

\subsection{Design Practical Courses}

The theory and practice of IoT are inseparable. To design a practical course, teachers have to develop a practical IoT platform that can support IoT projects. On such an IoT platform, the students and the teachers will derive effective practical training. The most effective way to test the learning effect is whether the students can apply the technology properly in large-scale IoT projects [22]. Practical course teaching can be designed by the following steps:

1. Building an IoT platform by university-enterprise cooperation, offering intern opportunities in the IoT enterprise that can be taken as practice cases, and letting students participate in actual projects and go through the workflow, adapting to the teamwork of the enterprise.

2. Adjusting the training plan according to the existing IoT platform. The theoretical teaching versus practical training trade-off governs future student practice. In most universities, a lack of practical training is a common problem. Institutions should try to increase the proportion of practical courses to provide more opportunities for the students to practice their skills.

3. Encouraging students to participate in science and technology competitions, IoT development projects, and other innovation programs that can cultivate students' comprehensive quality.

In summary, the training model connects the training objectives, curriculum system, and practical training platform in a virtuous circle between the market, universities, and IoT talent, as shown in Figure 5. Considering the expectations of enterprises, universities and institutions set up talent training objectives as per their own characteristics, build connections between theory and practice, and develop a sound curriculum system with the most relevant courses within the framework of the TKM-Map. In addition, various ways can be explored to improve students' practical skills by taking advantage of schoolenterprise cooperation, science and technology competitions, and innovation projects. The model shown in Figure 5 can be taken as a guide to cultivate IoT talent, which will allow undergraduate students to meet the demands of the market and industry. 


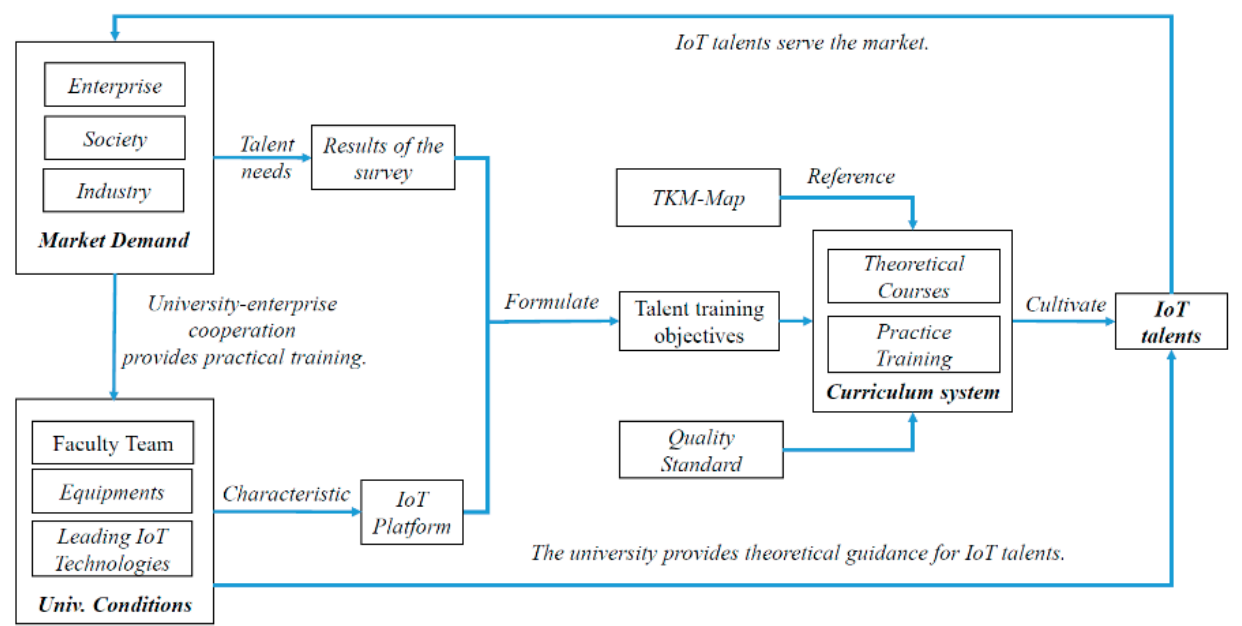

Figure 5. IoT talent training model.

\section{Discussions and Future Directions}

Because of the IoT's potential game-changing advantages across a wide range of applications and services, the IoT is expected to expand exponentially as the next global front network infrastructure, ultimately involving billions of connected devices and dozens of markets worldwide. However, as an emerging undergraduate major, pressing questions have yet to be answered as follows:

- The IoT is a system of systems, which involves a variety of software and hardware suppliers, system integrators, and service providers, and any part of it can be separately established as an independent major in the university. Therefore, the IoT is a collection of technologies such as Internet, mobile/wireless communication networks, sensor networks, and embedded control, which is an interdiscipline involving computers, communication technology, electronic information, measurement and control, and automation. For such a large and comprehensive undergraduate major, how much knowledge and skills students can acquire to apply what they have learned is worth pondering. It is also doubtful how in-depth things can be learned in such a large and comprehensive major. Moreover, if IoT Engineering is placed in the School of Computer Science, the courses designed are similar to those of Computer Science. If IoT Engineering is placed in the School of Electrical Engineering, Electronic Information, or Communications, the courses designed are similar to those of electronics-related majors. Regarding this situation, the university should be cautious to set up IoT Engineering, avoiding meaningless repetition and a new course just as a gimmick.

- Looking at the postgraduate entrance examination related to IoT Engineering, four directions are listed: (1) computer technology, (2) electronic science and technology, (3) computer science and technology, (4) electronics and communication engineering. In the case of a student who first applied for IoT Engineering (at undergraduate level), she/he would then return to these traditional disciplines when they want to further their studies, so why did she/he not directly apply for these majors and disciplines instead of IoT Engineering? Therefore, IoT Engineering is not just an undergraduate program. It needs to be designed and investigated further in both technologies and theories, and not to stand scrutiny-proof.

- The training goal of IoT Engineering is to cultivate advanced engineering talents who can systematically master the relevant theories, methods, and skills of the Internet of Things, and have broad professional knowledge in information fields such as communication technology, network technology, and sensor technology. The employment requirements of enterprise are: (1) hardware product design, which needs to be related to majors in electronic science and technology, communications, electronic information engineering, etc.; (2) embedded software, basically the same as above; (3) IoT software 
and hardware platforms, which are generally related to computer-related majors, software engineering, and network engineering majors. Obviously, the demand from enterprises for technology R\&D professionals is in these specific subdisciplines. How can graduates in such a broad major as IoT Engineering compete with graduates in these traditional subdivided majors? Besides, the requirements of large companies for technical R\&D talent are master's degree or above, but most universities do not have such IoT-related postgraduate programs.

- There has been no precise and commonly accepted definition of the IoT, and no consensus has been reached. The theoretical system of the IoT has not been fully established. For such a new and technologically innovating theory, it is most suitable to set up laboratories in universities and to set up corresponding theoretical and experimental courses in existing related majors for students to understand.

However, the IoT is known as the third wave of the world's information industry and represents the next generation of information technology. The IoT is a convergent application and technological improvement that appears after the development of modern information technologies to a certain stage. The convergence and integrated application of network technologies, artificial intelligence, and automation technologies enables intelligent dialogue between humans and things, and thus creates a smart world. We summarize the following trends in IoT Engineering below.

\subsection{AI Courses Embracing a Boom}

We are witnessing revolutionary progress in advanced IoT technologies brought by AI. With the popularization of IoT devices, the data collected by these IoT devices will grow exponentially, resulting in requirements for massive smart data storage and processing. The traditional data processing technologies no longer meet the requirements of enterprises. AI-enabled data processing can achieve better performance and create more application scenarios and business opportunities. Therefore, it is inevitable that there will be new courses or increases in the number of courses on artificial intelligence, machine learning, and deep learning in IoT education.

\subsection{Edge Computing Becoming the Hot Topic}

With the staggering increase in data volume and diversified requirements of data processing, edge computing has an important role in balancing the available resources of power, storage, and communication $[31,35,36]$. Edge computing collects and processes data locally, instead of transmitting them to the cloud, and it is close to the user, which enables real-time processing and faster access to information. Therefore, edge computing reduces data exchange with cloud servers and balances the amount of data to be processed, hence making it low-cost and low-bandwidth. Moreover, edge computing has better privacy protection capabilities. Therefore, distributed edge computing should be added to the curriculum and account for a larger proportion compared with cloud computing.

\subsection{IoT Security Drawing Attention}

Every coin has two sides. The proliferation of IoT devices, the data they generate, and the wireless infrastructure they rely on bring dramatic and unprecedented change to our lives. In addition, the breakneck pace of IoT development poses a threat to security, and thus privacy technologies are needed to ensure safe and appropriate use of IoT. Frequent information leaks have aroused global concern and call for urgent secure protection countermeasures. Thus, if not an independent department in the university, IoT security must be an indispensable part of the curriculum [37].

\section{Conclusions}

We have presented an overview of the history and status of IoT undergraduate programs in China and analyzed current problems. To solve these problems, we suggested a TKM-Map, which contains a four-layer model and two supporting modules as a guide 
for universities and institutions to formulate their IoT curricula. Then, the core courses that each tier requires to be mastered are detailed. Relying on the TKM-Map, we propose a closed-loop approach to building IoT Engineering curricula. Taking the demands of enterprises and the characteristics of the universities as the starting point, a reasonable IoT Engineering curriculum is created with the guidance of the TKM-Map and consolidated on the IoT practical platform of university-enterprise cooperation.

IoT education is an emerging realm with little experience for reference. At present, only China regards IoT Engineering as a stand-alone undergraduate program in universities on a large scale. This survey of IoT Engineering undergraduate programs in Chinese universities can prompt Chinese educators to reflect on their achievements and problems and share their experiences of IoT education with other countries, which will contribute to the promotion of IoT talent worldwide.

Author Contributions: B.D. contributed significantly analysis and wrote the manuscript; H.N. contributed to the conception of the study; Y.C. collected the data and prepared manuscript; W.H. performed the data analysis; R.Z. performed English polishing. All authors have read and agreed to the published version of the manuscript.

Funding: This research was funded the National Natural Science Foundation of China under Grant U1633121 and University of Science and Technology Course Fund KC2019SZ11.

Institutional Review Board Statement: Not applicable.

Informed Consent Statement: Not applicable.

Data Availability Statement: Data sharing not applicable.

Conflicts of Interest: The authors declare no conflict of interest.

\section{References}

1. Gubbi, J.; Buyya, R.; Marusic, S.; Palaniswami, M. Internet of Things (IoT): A vision, architectural elements, and future directions. Future Gener. Comput. Syst. 2013, 29, 1645-1660. [CrossRef]

2. Gershenfeld, N.A.; Gershenfeld, N. When Things Start to Think; Macmillan: New York, NY, USA, 2000.

3. Peña-López, I. ITU Internet Report 2005: The Internet of Things; ITU: Geneve, Switzerland, 2005.

4. Liu, Y.; Zhou, G. Key technologies and applications of internet of things. In Proceedings of the 2012 Fifth International Conference on Intelligent Computation Technology and Automation, Zhangjiajie, China, 12-14 January 2012; pp. 197-200.

5. Ning, H.; Hu, S. Technology classification, industry, and education for Future Internet of Things. Int. J. Commun. Syst. 2012, 25, 1230-1241. [CrossRef]

6. Zarei, M.; Mohammadian, A.; Ghasemi, R. Internet of things in industries: A survey for sustainable development. Int. J. Innov. Sustain. Dev. 2016, 10, 419-442. [CrossRef]

7. Chen, S.; Xu, H.; Liu, D.; Hu, B.; Wang, H. A Vision of IoT: Applications, Challenges, and Opportunities with China Perspective. IEEE Internet Things J. 2014, 1, 349-359. [CrossRef]

8. Akbar, M.A.; Rashid, M.M. Technology based learning system in internet of things (iot) education. In Proceedings of the 2018 7th International Conference on Computer and Communication Engineering (ICCCE), Kuala Lumpur, Malaysia, 19-20 September 2018; pp. 192-197.

9. Probst, A.; Grafinger, M.; Schachinger, G.; Bernsteiner, R. Education of IoT-Engineering in Austrian Vocational Secondary Schools. In International Conference on Interactive Collaborative Learning, Bangkok, Thailand, 25-28 September 2019; Springer: Cham, Switzerland, 2019; pp. 309-318.

10. Burd, B.; Barker, L.; Pérez, F.A.F.; Russell, I.; Siever, B.; Tudor, L.; McCarthy, M.; Pollock, I. The internet of things in undergraduate computer and information science education: Exploring curricula and pedagogy. In Proceedings Companion of the 23rd Annual ACM Conference on Innovation and Technology in Computer Science Education; Association for Computing Machinery: New York, NY, USA, 2018; pp. 200-216.

11. Selvaragavan, A. Primary Hurdles for IoT Companies in Recruiting Talent/Leadership and Aligning Culture. 2018. Available online: https:/ / www.thingsofiot.com/blog/primary-hurdles-for-iot-companies-in-recruiting-talent-leadership-and-aligningculture (accessed on 25 April 2021).

12. Industrial Internet of Things (IIoT). Available online: https:/ /www.ptc.com/en/products/iiot (accessed on 25 August 2020).

13. Ning, H. Cyberspace Data and Intelligence, and Cyber-Living, Syndrome, and Health. In proceedings of the International 2019 Cyberspace Congress, CyberDI and CyberLife, Beijing, China, 16-18 December 2019; Springer Nature: Basingstoke, UK, 2020; Volume 1138. 
14. Ministry of Science and Technology of the People's Republic of China. China Science and Technology Development Report 2009; Ministry of Science and Technology of the People's Republic of China: Beijing, China, 2010.

15. Miao, Y. Thinking about Specialty Setting for the Internet of Things in Institutions of Higher Learning. Comput. Knowl. Technol. 2011, 28, 7046-7047.

16. Wang, B. Chinese 4-Year College Graduates Employment Annual Report (2020); Social Science Academic Press (China): Beijing, China, 2020.

17. Liu, J.; Chen, X. Internet of Things Engineering: Let Everything Talk. Available online: https://gaokao.chsi.com.cn/gkxx/zybk/ zt/201212/20121207/373453679.html (accessed on 10 May 2020).

18. Ning, H.; Hu, S. Internet of Things: An Emerging Industrial or a New Major? In Proceedings of the 2011 International Conference on Internet of Things and 4th International Conference on Cyber, Physical and Social Computing, Dalian, China, 19-22 October 2011; pp. 178-183.

19. The Designated Platform of the Ministry of Education's College Entrance Examination Sunshine Project Website. Available online: https:/ / gaokao.chsi.com.cn/ (accessed on 25 August 2020).

20. Ghadeer, H. Cybersecurity issues in internet of things and countermeasures. In Proceedings of the 2018 IEEE International Conference on Industrial Internet (ICII), Seattle, WA, USA, 21-23 October 2018; pp. 195-201.

21. Huang, D. Research on the Curriculum Setting of the Internet of Things Major in the Context of New Engineering. Comput. Educ. 2018, 3, 68-72.

22. Yan, X. Research and Practice on Teaching Reform of Internet of Things Technology and Application Course. Course Educ. Res. 2019, 5, 92-93.

23. Ren, X. Construction of Hardware Course Group for the Internet of Things Engineering. Mircrocomupter Appl. 2018, 34, 40-42.

24. IoT Engineering Website. Available online: http://scce.ustb.edu.cn/jiaoyujiaoxue/benkeshengpeiyang/wulianwanggongcheng/ (accessed on 25 August 2020).

25. School of Computer Science Website. Available online: http://cs.whu.edu.cn/jiaoxue_show.aspx?id=3 (accessed on 25 August 2020).

26. Evaluation Report on the Quality of Fresh Graduates from University of Science and Technology Beijing. 2018. Available online: https://job.ustb.edu.cn/uploadfile/ustb/admin/default/upload_file_32301.pdf (accessed on 20 August 2019).

27. Al-Emran, M.; Malik, S.I.; Al-Kabi, M.N. A Survey of Internet of Things (IoT) in Education: Opportunities and Challenges. In Toward Social Internet of Things (SIoT): Enabling Technologies, Architectures and Applications; Springer: Cham, Switzerland, 2020; pp. 197-209.

28. Samie, F.; Bauer, L.; Henkel, J. IoT technologies for embedded computing: A survey. In Proceedings of the 2016 International Conference on Hardware/Software Codesign and System Synthesis (CODES+ ISSS), Pittsburgh, PA, USA, 2-7 October 2016; pp. 1-10.

29. Hwang, Y.H. Iot security \& privacy: Threats and challenges. In Proceedings of the 1st ACM Workshop on IoT Privacy, Trust, and Security; Association for Computing Machinery: New York, NY, USA, 2015; p. 1.

30. Huang, X.; Craig, P.; Lin, H.; Yan, Z. SecIoT: A security framework for the Internet of Things. Secur. Commun. Netw. 2016, 9, 3083-3094. [CrossRef]

31. Chiang, M.; Zhang, T. Fog and IoT: An Overview of Research Opportunities. IEEE Internet Things J. 2016, 3, 854-864. [CrossRef]

32. Kim, J.H. A Survey of IoT Security: Risks, Requirements, Trends, and Key Technologies. J. Ind. Integr. Manag. 2017, 2, 1750008. [CrossRef]

33. Zhang, C.; Green, R. Communication security in internet of thing: Preventive measure and avoid DDoS attack over IoT network. In Proceedings of the 18th Symposium on Communications \& Networking, Alexandria VA, USA, 12-15 April 2015; Society for Computer Simulation International: San Diego, CA, USA, 2015; pp. 8-15.

34. Apthorpe, N.; Reisman, D.; Feamster, N. A smart home is no castle: Privacy vulnerabilities of encrypted iot traffic. arXiv 2017, arXiv:1705.06805.

35. Ren, J.; Guo, H.; Xu, C.; Zhang, Y. Serving at the Edge: A Scalable IoT Architecture Based on Transparent Computing. IEEE Netw. 2017, 31, 96-105. [CrossRef]

36. El-Sayed, H.; Sankar, S.; Prasad, M.; Puthal, D.; Gupta, A.; Mohanty, M.; Lin, C.-T. Edge of Things: The Big Picture on the Integration of Edge, IoT and the Cloud in a Distributed Computing Environment. IEEE Access 2018, 6, 1706-1717. [CrossRef]

37. Mavromoustakis, C.X.; Mastorakis, G.; Batalla, J.M. Internet of Things (IoT) in 5G mobile Technologies; Springer: Cham, Switzerland, 2016; Volume 8. 